\title{
INTERNATIONAL SYMPOSIUM ON
}

\section{'STRUCTURES IN MATHEMATICAL THEORIES'}

San Sebastián (Spain), 24th-28th September 1990

\author{
Organized by the Department of Logic and Philosophy \\ of Science, University of the Basque Country
}

\section{PAE-ANNOUNCEMENT}

The notion of scientific theory is essential for the analysis and rational reconstruction of empirical theories. Howewer, in the case of Mathematics, and more generally in the Formal Sciences, the concept of theory itself becomes problematic. In its place, terms like 'structures', 'calculus', etc. are sometimes preferred. Nevertheless, to some branches of Mathematics such as the Number Theory, Computer Sciences, Artificial Intelligence, etc. an empirical methodology is applied: conjectures, observation, corroboration and refutation of hypothesis, experimentation and even technology are not outside the boundaries of mathematical research. is it possible, therefore, to reconstruct mathematical theories according to the methods of analysis for empirical theories proposed by philosophers of science in recent years? What relationship does Mathematics have with empirical sciences and with reality? How do mathematicians research?

An International Symposium on the aforementioned issues will be held in San Sebastian from 24th to 28th of September 1990, in order that an open platform can be offered to mathematicians, philosophers of science and historians of science to discuss the singularity of mathematical theories: their structures, historical evolutions, and interrelations with other sciences and technologies. The papers and discussions will be published.

The Symposium will consist of five sections:

I: Mathematical Theories and Empirical Theories.

II: Applications of Mathematical Theories.

III: History and Sociology of Mathematica! Theories.

IV: Methods of research into Mathematics.

V: Structures of Mathematical Theories.

The Symposium will be organized by the Department of Logic and Philosophy of Science at the University of the Basque Country. The First Circular will be sent out in May 1989.

All correspondence should by adressed to:

Prof. Javier Echeverria and/or Andoni lbarra

Departamento de Lógica y Filosofía de la Ciencia.

Universidad del Pais Vasco/Euskal Herriko Unibertsitatea.

Apartado 1249.

20080 San Sebastián (SPAIN) 